\title{
Análise do Acórdão Proferido pelo Superior Tribunal de Justiça no REsp 1251697/PR - Incidência do Princípio da Intranscendência da Pena em Caso de Multa por Desmatamento
}

\author{
RODRIGO TEIXEIRA ANTUÑA \\ Mestrando em Direito pela Escola Superior Dom Helder Câmara, Graduado em Direito pela \\ Universidade Federal de Minas Gerais (1999), Graduado em Medicina Veterinária (1992), \\ também pela UFMG, Delegado de Polícia Federal do Departamento de Polícia Federal desde \\ 0 ano de 2003. Tem experiência na área de Direito, com ênfase em Direito Penal. Atuou nas \\ Delegacias de Combate aos Crimes Ambientais e de Defesa Institucional, bem como efetuou \\ trabalhos na área de gestão de pessoas dentro do citado Departamento. Atualmente atua na \\ Delefaz - Delegacia de Combate aos Crimes Fazendários, em Belo Horizonte/MG.
}

Submissão: 11.03 .2013

Decisão Editorial: 20.05.2013

RESUMO: A pesquisa é centrada em uma perspectiva democrática que compreende o princípio da responsabilidade pessoal da pena como fator de garantia de direitos fundamentais do cidadão. Discutiu-se, tendo em vista acórdão proferido pelo Superior Tribunal de Justiça, a problemática das obrigações propter rem nos casos de responsabilidade civil por danos ambientais. Da mesma maneira, analisou-se a questão da aplicação das penas nas hipóteses de crimes e infrações administrativas ambientais. 0 estudo discutiu se em tais hipóteses tais sanções poderiam ser cobradas de pessoas diferentes dos autores do fato. 0 artigo sustentou que as normas previstas no caput do art. 14 da Lei $n^{0}$ 6.938/1981 e na Lei n 9.605/1998 reforçam a aplicação da teoria da culpabilidade na aplicação de sanções penais e administrativas ambientais, afastando-se a teoria da responsabilidade objetiva em tais casos, devendo tal teoria ser aplicada somente nas hipóteses de reparação civil por dano ambiental.

PALAVRAS-CHAVE: Leis nºs 6.938/1981 e 9.605/1998; Sanções penais e administrativas ambientais; Princípio da responsabilidade pessoal da pena.

ABSTRACT: The research is centered on a democratic perspective that understands the principle of personal responsibility of the sentence as a factor of guarantee of fundamental rights of the citizen. It was discussed in view of the judgment of the Superior Court of Justice, the issue of propter rem obligations in cases of civil responsibility for environmental damage. Similarly, we analyzed the question of the application of penalties in cases of environmental crimes and administrative violations. The study debated if in these cases these sanctions could be collected from persons other than the authors of fact. The article argued that the rules of caput of art. 14 of Law $n^{0} 6.938 / 1981$ and Law $n^{0} 9.605 / 1998$ reinforce the application of the theory of culpability in criminal sanctions and administrative environment, away from the theory of objective responsibility in such cases. This theory should be applied only in cases of civil remedies for environmental damage. 
KEYWORDS: Laws nº 6.938/1981 and 9.605/1998; criminal sanctions and administrative environment; principle of personal responsibility of the sentence.

SUMÁRIO: Introdução; 1 Responsabilidade civil por dano ambiental; 2 Penalidades administrativas e penais; Conclusão; Referências.

\section{INTRODUÇÃO}

O presente artigo tem como objetivo analisar o acórdão proferido pelo Superior Tribunal de Justiça, no REsp 1251697/PR, tendo como Relator o Ministro Mauro Campbell Marques. A ementa do citado acórdão foi publicada em 17.04.2012, com o seguinte teor, naquilo que interessa:

\section{AMBIENTAL - RECURSO ESPECIAL - MULTA APLICADA ADMINISTRATIVA- MENTE EM RAZÃO DE INFRAÇÃO AMBIENTAL - EXECUÇÃO FISCAL AJUIZA- DA EM FACE DO ADQUIRENTE DA PROPRIEDADE - ILEGITIMIDADE PASSIVA - MULTA COMO PENALIDADE ADMINISTRATIVA, DIFERENTE DA OBRIGA- ÇÃO CIVIL DE REPARAR O DANO}

1. Trata-se, na origem, de embargos à execução fiscal ajuizado pelo ora recorrente por figurar no polo passivo de feito executivo levado a cabo pelo Ibama para cobrar multa aplicada por infração ambiental.

$[\ldots]$

5. Esta Corte Superior possui entendimento pacífico no sentido de que a responsabilidade civil pela reparação dos danos ambientais adere à propriedade, como obrigação propter rem, sendo possível cobrar também do atual proprietário condutas derivadas de danos provocados pelos proprietários antigos. Foi essa a jurisprudência invocada pela origem para manter a decisão agravada.

6. O ponto controverso nestes autos, contudo, é outro. Discute-se, aqui, a possibilidade de que terceiro responda por sanção aplicada por infração ambiental.

7. A questão, portanto, não se cinge ao plano da responsabilidade civil, mas da responsabilidade administrativa por dano ambiental.

8. Pelo princípio da intranscendência das penas (art. 5º , inciso XLV, CR/1988), aplicável não só ao âmbito penal, mas também a todo o direito sancionador, não é possível ajuizar execução fiscal em face do recorrente para cobrar multa aplicada em face de condutas imputáveis a seu pai.

9. Isso porque a aplicação de penalidades administrativas não obedece à lógica da responsabilidade objetiva da esfera cível (para reparação dos danos causados), mas deve obedecer à sistemática da teoria da culpabilidade, ou seja, a conduta deve ser cometida pelo alegado transgressor, com demonstração de seu elemento subjetivo, e com demonstração do nexo causal entre a conduta e o dano.

10. A diferença entre os dois âmbitos de punição e suas consequências fica bem estampada da leitura do art. 14, § 1ํㅡㄹ da Lei $n^{\circ}$ 6.938/1981, segundo o qual "[s]em obstar a aplicação das penalidades previstas neste artigo [entre elas, frise-se, a multa], é o poluidor obrigado, independentemente da existência de culpa, 
a indenizar ou reparar os danos causados ao meio ambiente e a terceiros, afetados por sua atividade".

11. O art. 14, caput, também é claro: "[s]em prejuízo das penalidades definidas pela legislação federal, estadual e municipal, o não cumprimento das medidas necessárias à preservação ou correção dos inconvenientes e danos causados pela degradação da qualidade ambiental sujeitará os transgressores: [...]".

$[\ldots]$

13. Note-se que nem seria necessária toda a construção doutrinária e jurisprudencial no sentido de que a obrigação civil de reparar o dano ambiental é do tipo propter rem, porque, na verdade, a própria lei já define como poluidor todo aquele que seja responsável pela degradação ambiental - e aquele que, adquirindo a propriedade, não reverte o dano ambiental, ainda que não causado por ele, já seria um responsável indireto por degradação ambiental (poluidor, pois).

14. Mas fato é que o uso do vocábulo "transgressores" no caput do art. 14, comparado à utilização da palavra "poluidor" no $§ 1^{\circ}$ do mesmo dispositivo, deixa a entender aquilo que já se podia inferir da vigência do princípio da intranscendência das penas: a responsabilidade civil por dano ambiental é subjetivamente mais abrangente do que as responsabilidades administrativa e penal, não admitindo estas últimas que terceiros respondam a título objetivo por ofensas ambientais praticadas por outrem.

15. Recurso especial provido.

O problema proposto foi investigado por meio de pesquisa de cunho qualitativo, com abordagem descritiva, utilizando-se de técnica de ampla pesquisa bibliográfica, incluindo-se consultas a legislações constitucionais e infraconstitucionais, bem como leitura e análise de doutrinas e artigos nacionais. Entendemos então que a metodologia fenomenológica foi tratada no presente trabalho, como forma de resgatar a discussão sobre o princípio da intranscendência das penas, tanto nos casos de infrações penais e administrativas ambientais como na hipótese de reparação civil por dano ambiental, à luz da Constituição Federal de 1988.

Trata-se, portanto, de acórdão proferido em sede de recurso especial, interposto por José Antônio Magarinos Bello em face do Ibama - Instituto Brasileiro do Meio Ambiente e dos Recursos Naturais Renováveis, tendo em vista decisão proferida pelo Tribunal Regional da $4^{a}$ Região que entendeu ser a responsabilidade civil ambiental objetiva, solidária e propter rem, respondendo pelos danos ao meio ambiente perpetrados antes da alienação do imóvel tanto o alienante quanto o adquirente. De acordo com o voto do Ministro Relator dessa última decisão, foram opostos embargos "contra execução fiscal ajuizada para cobrança de multa imposta pelo Ibama por infração à legislação ambiental (desmatamento)". 
Verifica-se que o recorrente interpôs, na origem, embargos à execução fiscal movida pelo Ibama, pleiteando sua ilegitimidade em figurar no polo passivo da demanda, uma vez que a citada execução foi intentada com o fito de cobrar multa lavrada por infração ambiental, prevista no art. 50 c/c art. 25 da Lei no 9.605/1998 e art. 14 da Lei $n^{\circ}$ 6.938/1981, infração esta cometida por seu pai, dono do imóvel à época. Assim, em sede de recurso especial, alegou violação aos arts. $3^{\circ}$ e 568 , inciso I, do Código de Processo Civil (CPC) e 3º, inciso IV, e 14 da Lei no 6.938/1981.

Segundo o Ministro Relator do Superior Tribunal de Justiça, o Tribunal a quo entendeu ser o caráter propter rem e solidário das obrigações ambientais suficiente para justificar a responsabilidade do recorrente pelo pagamento da multa imposta por infração ambiental, em sede de execução fiscal, mesmo a infração tendo sido cometida e lançada em face de seu pai. Entretanto, concluiu não se poder confundir a responsabilidade civil por danos ambientais, de caráter objetivo, com a responsabilidade por sanção imposta devido o cometimento de uma infração ambiental, de caráter subjetivo. Segundo o voto do ilustre Relator, a aplicação de penalidades administrativas deve obedecer à sistemática da teoria da culpabilidade, ou seja, "a conduta deve ser cometida pelo alegado transgressor, com demonstração de seu elemento subjetivo, e com demonstração do nexo causal entre a conduta e o dano". Dessa forma, não poderia o recorrente, não responsável pela realização da conduta sancionada pelo Estado, responder por tal fato, já que se estaria aplicando a responsabilidade objetiva ao caso, contrariando-se toda a dogmática do direito sancionador.

Além disso, o referido acórdão baseou-se no contido tanto no caput do art. 14 da Lei $n^{\circ}$ 6.938/1981 quanto no seu § 1ํ para fazer tal distinção. No caput, o uso do vocábulo "transgressores" denota que a aplicação e a execução das penas limitam-se aos transgressores, vale dizer, aplica-se o princípio da intranscendência das penas, previsto no art. 5o, inciso XLV, da Constituição Federal de 1988. Já o vocábulo "poluidores", utilizado no

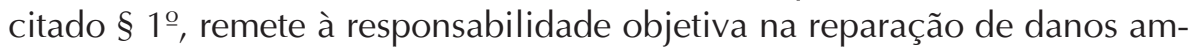
bientais.

\section{RESPONSABILIDADE CIVIL POR DANO AMBIENTAL}

Conforme ensina Celso Antonio Pacheco Fiorillo, "a responsabilidade civil pelos danos causados ao meio ambiente é do tipo objetiva", justificando que a parte final do art. 225, § 3º , da Constituição Federal de 1988 não exige qualquer elemento subjetivo para a configuração da responsabilidade civil (Fiorillo, 2007, p. 50). Reza o referido parágrafo que 
as condutas e atividades consideradas lesivas ao meio ambiente sujeitarão os infratores pessoas físicas ou jurídicas a sanções penais e administrativas, independentemente da obrigação de reparar os danos causados.

Nesse mesmo sentido, Paulo Affonso Leme Machado esclarece não ser necessária a análise da culpa para haver a reparação ou indenização de danos causados ao meio ambiente. Confira-se:

A responsabilidade objetiva ambiental significa que quem danificar o ambiente tem o dever jurídico de repará-lo. Presente, pois, o binômio dano/reparação. Não se pergunta a razão da degradação para que haja o dever de indenizar e/ou reparar. A responsabilidade sem culpa tem incidência na indenização ou na reparação dos "danos causados ao meio ambiente e aos terceiros afetados por sua atividade" (art. 14, § 1을 da Lei no 9.938/1981) (Machado, 2010, p. 361)

Confirmando tais posicionamentos, a Lei da Política Nacional do Meio Ambiente (Lei $n^{\circ}$ 6.938/1981) instituiu, de forma expressa, o regime de responsabilidade objetiva pelo dano ambiental, ao dispor no $\S 1^{\circ}$ do art. 14 que,

sem obstar a aplicação das penalidades previstas neste artigo, é o poluidor obrigado, independentemente de existência de culpa, a indenizar ou reparar os danos causados ao meio ambiente e a terceiros, efetuados por sua atividade. O Ministério Público da União e dos Estados terá legitimidade para propor ação de responsabilidade civil e criminal por danos causados ao meio ambiente.

De acordo com Antonio Herman V. Benjamin, o citado artigo objetivou a responsabilidade civil bem como conferiu legitimidade ao Ministério Público para efetuar a cobrança de eventual reparação ambiental, legitimação esta que seria ampliada por meio da Lei da Ação Civil Pública para outras entidades (Benjamin, 2011, p. 99).

Ainda segundo tal autor, o direito brasileiro faz uso de várias técnicas de responsabilidade civil pelo dano ambiental. Algumas podem ser consideradas autônomas e imediatas, como, por exemplo, a prevista no referido $\S 1^{\circ}$ do art. 14 da Lei $n^{\circ} 6.938 / 1981$, que se utiliza de procedimento processual próprio, tal como ação civil pública ou individual, sem que seja necessária a alegação de culpa para obter a obrigação reparatória (Benjamin, 2011, p. 103/104). Esse instrumento autônomo possui a função primeira de reconstituir tanto quanto possível o status quo ante, objetivando de maneira direta a reparação natural ou cível pelo dano causado. Dessa maneira, não há a intermediação de outras disciplinas jurídicas como o processo penal ou direito administrativo, com a inflição de uma pena para obter a reparação do dano.

Entretanto, por meio da edição da Lei no 9.605/1998, o citado autor identificou técnicas de responsabilização civil, dependentes e mediatas, 
"posto que não estabelecidas diretamente, sendo produtos ora da implementação penal, ora da implementação administrativa" (Benjamin, 2011, p. 104).

Assim, se "a reparação sucede no âmbito do processo penal, a culpa latu sensu é da sua essência, conquanto a persecução penal pressupõe, pelo menos em tese, a existência de dolo ou culpa strictu sensu" (Benjamin, 2011, p. 105). De outro lado, se o pedido reparatório vem apartado do processo penal, seu regime jurídico será objetivo ( $\$ 1^{\circ}$ do art. 14 da Lei $\mathrm{n}^{\mathrm{o}} 6.938 / 1981$ ).

Referido autor ainda defende a "possibilidade de penalização civil", prevista no art. $3^{\circ}$ da Lei $n^{\circ}$ 9.605/1998, que dispõe serem as pessoas jurídicas e naturais responsabilizadas administrativa, civil e penalmente (Benjamin, 2011, p. 108). Assim, na referida Lei no 9.605/1998, existiriam, concomitantemente, a responsabilidade civil dependente da persecutio criminis e a própria multa civil, ambas submetidas a um regime de culpa, já que disparadas por um processo penal.

Em resumo, o citado autor classifica o sistema de responsabilização do poluidor com as seguintes linhas básicas:

[...] a) responsabilidade civil pelo dano ambiental (pessoal - patrimonial ou moral - e/ou ecológico), com base na Lei $n^{\circ}$ 6.938/1981 (regime objetivo), acrescida da inovadora possibilidade de juiz cível, em complementação ao quantum debeatur indenizatório, impor ao réu multa civil, esta com base na Lei no 9.605/1998, desde que presente infração a qualquer dos dispositivos do novo estatuto; e b) responsabilidade penal e administrativa nos termos da Lei no 9.605/1998 (regime subjetivo para os ilícitos penais), além de outras sanções previstas no restante do ordenamento [...]. (Benjamin, 2011, p. 108).

Importante frisar que na responsabilidade civil por danos ambientais (objetiva), a obrigação é propter rem, ou seja, adere à propriedade. Isso significa que a obrigação segue o bem (a coisa), passando do antigo proprietário ao novo que adquire junto com o bem o dever de satisfazer a obrigação. A obrigação propter rem é transmitida juntamente com a propriedade e o seu cumprimento é da responsabilidade do titular, independente de ter origem anterior à transmissão do domínio. Conforme Sebastião José de Assis Neto, quem adquire área desmatada "será responsabilizado pela reparação desse dano ambiental ainda que se demonstre que o desmatamento tenha sido promovido pelo(s) antigo(s) (ou antigos - é bom que se diga) proprietário(s)". Ainda segundo tal autor, "independentemente de quem tenha sido o causador da lesão, a recomposição dessa espécie de área se caracteriza como obrigação propter rem e, portanto, acompanha a coisa com quem quer que ela esteja" (Neto, 2010, p. 12). 
Segundo essa linha de raciocínio, confira-se acórdão do Superior Tribunal de Justiça, proferido no REsp 1090968/SP, Relator o Ministro Luiz Fux, DJe de 03.08.2010, naquilo que interessa:

PROCESSUAL CIVIL - ADMINISTRATIVO - DANOS AMBIENTAIS - AÇÃO CIVIL PÚBLICA - RESPONSABILIDADE DO ADQUIRENTE - TERRAS RURAIS RECOMPOSIÇÃO - MATAS - TEMPUS REGIT ACTUM - AVERBAÇÃO PERCENTUAL DE 20\% - SÚMULA № 7 DO STJ

1. A responsabilidade pelo dano ambiental é objetiva, ante a ratio essendi da Lei $n^{\circ}$ 6.938/1981, que em seu art. $14, \S 1^{\circ}$, determina que o poluidor seja obrigado a indenizar ou reparar os danos ao meio ambiente e, quanto ao terceiro, preceitua que a obrigação persiste, mesmo sem culpa. Precedentes do STJ: REsp 826976/PR, Rel. Min. Castro Meira, DJ de 01.09.2006; AgRg-REsp 504626/PR, Rel. Min. Francisco Falcão, DJ de 17.05.2004; REsp 263383/PR, Rel. Min. João Otávio de Noronha, DJ de 22.08.2005; e EDcl-AgRg-REsp 255170/SP, desta relatoria, DJ de 22.04.2003.

2. A obrigação de reparação dos danos ambientais é propter rem, por isso que a Lei $n^{\circ} 8.171 / 1991$ vigora para todos os proprietários rurais, ainda que não sejam eles os responsáveis por eventuais desmatamentos anteriores, máxime porque a referida norma referendou o próprio Código Florestal (Lei no 4.771/1965), que estabelecia uma limitação administrativa às propriedades rurais, obrigando os seus proprietários a instituírem áreas de reservas legais, de no mínimo $20 \%$ de cada propriedade, em prol do interesse coletivo. Precedente do STJ: REsp 343.741/PR, Rel. Min. Franciulli Netto, DJ de 07.10.2002.

3. Consoante bem pontuado pelo Ministro Herman Benjamin, no REsp 650728/SC, $2^{\underline{a}}$ Turma, unânime: "[...] 11. É incompatível com o Direito brasileiro a chamada desafetação ou desclassificação jurídica tácita em razão do fato consumado. 12. As obrigações ambientais derivadas do depósito ilegal de lixo ou resíduos no solo são de natureza propter rem, o que significa dizer que aderem ao título e se transferem ao futuro proprietário, prescindindo-se de debate sobre a boa ou má-fé do adquirente, pois não se está no âmbito da responsabilidade subjetiva, baseada em culpa. 13. Para o fim de apuração do nexo de causalidade no dano ambiental, equiparam-se quem faz, quem não faz quando deveria fazer, quem deixa fazer, quem não se importa que façam, quem financia para que façam, e quem se beneficia quando outros fazem. 14. Constatado o nexo causal entre a ação e a omissão das recorrentes com o dano ambiental em questão, surge, objetivamente, o dever de promover a recuperação da área afetada e indenizar eventuais danos remanescentes, na forma do art. 14 , $\S 1^{\circ}$, da Lei $n^{\circ}$ 6.938/1981. [...]". DJ 02.12.2009.

4. Paulo Affonso Leme Machado, em sua obra Direito ambiental brasileiro, ressalta que "[...] a responsabilidade objetiva ambiental significa que quem danificar o ambiente tem o dever jurídico de repará-lo. Presente, pois, o binômio dano/reparação. Não se pergunta a razão da degradação para que haja o dever de indenizar e/ou reparar. A responsabilidade sem culpa tem incidência na indenização ou na reparação dos "danos causados ao meio ambiente e aos terceiros afetados por sua atividade" (art. 14, § $3^{\circ}$, da Lei $n^{\circ}$ 6.938/1981). Não interessa que tipo de obra ou atividade seja exercida pelo que degrada, pois não há necessidade de 
que ela apresente risco ou seja perigosa. Procura-se quem foi atingido e, se for o meio ambiente e o homem, inicia-se o processo lógico-jurídico da imputação civil objetiva ambienta!. Só depois é que se entrará na fase do estabelecimento do nexo de causalidade entre a ação ou omissão e o dano. É contra o Direito enriquecer-se ou ter lucro à custa da degradação do meio ambiente. O art. 927, parágrafo único, do CC de 2002 dispõe: "Haverá obrigação de reparar o dano, independentemente de culpa, nos casos especificados em lei, ou quando a atividade normalmente desenvolvida pelo autor do dano implicar, por sua natureza, risco para os direitos de outrem". Quanto à primeira parte, em matéria ambiental, já temos a Lei $n^{\circ} 6.938 / 1981$, que instituiu a responsabilidade sem culpa. Quanto à segunda parte, quando nos defrontarmos com atividades de risco, cujo regime de responsabilidade não tenha sido especificado em lei, o juiz analisará, caso a caso, ou o Poder Público fará a classificação dessas atividades. "É a responsabilidade pelo risco da atividade". Na conceituação do risco aplicam-se os princípios da precaução, da prevenção e da reparação. Repara-se por força do direito positivo e, também, por um princípio de direito natural, pois não é justo prejudicar nem os outros e nem a si mesmo. Facilita-se a obtenção da prova da responsabilidade, sem se exigir a intenção, a imprudência e a negligência para serem protegidos bens de alto interesse de todos e cuja lesão ou destruição terá consequências não só para a geração presente, como para a geração futura. Nenhum dos poderes da República, ninguém, está autorizado, moral e constitucionalmente, a concordar ou a praticar uma transação que acarrete a perda de chance de vida e de saúde das gerações[...]" (Direito ambiental brasileiro. Malheiros Editores, 12. ed., 2004, p. 326-327).

5. A Constituição Federal consagra em seu art. 186 que a função social da propriedade rural é cumprida quando atende, seguindo critérios e graus de exigência estabelecidos em lei, a requisitos certos, entre os quais o de "utilização adequada dos recursos naturais disponíveis e preservação do meio ambiente".

6. A adoção do princípio tempus regit actum impõe obediência à lei em vigor quando da ocorrência do fato.

7. In casu, os fatos apurados como infração ambiental ocorreram no ano de 1997, momento em que já se encontrava em vigor o Código Florestal Lei oㅡ 4.771/1965, não havendo que se perquirir quanto à aplicação do Decreto oㅜ 23.793/1994, que inclusive foi revogado por aquela lei.

$[\ldots]$

12. Recurso parcialmente conhecido e, nesta parte, desprovido.

\section{PENALIDADES ADMINISTRATIVAS E PENAIS}

Segundo Paulo Affonso Leme Machado, a Lei no 9.605/1998 "trata, especialmente, de crimes contra o meio ambiente e de infrações administrativas ambientais" (Machado, 2010, p. 737).

Conforme o art. 5º, inciso XLV, da Constituição Federal de 1988, "nenhuma pena passará da pessoa do condenado, podendo a obrigação de 
reparar o dano e a decretação do perdimento de bens ser, nos termos da lei, estendidas aos sucessores e contra ele executadas, até o limite do valor do patrimônio transferido".

De tal artigo extrai-se o princípio da responsabilidade pessoal ou da intranscendência da pena, vale dizer, somente o condenado pode ser submetido à sanção aplicada pelo Estado. Rogério Greco, comentando tal tema, esclarece que o citado princípio constitucional quer dizer que,

quando a responsabilidade do condenado é penal, somente ele, e mais ninguém, poderá responder pela infração praticada. Qualquer que seja a natureza da penalidade aplicada - privativa de liberdade, restritiva de direitos ou multa -, somente o condenado é que deverá cumpri-la. (Greco, 2000, p. 75)

Especificamente sobre a pena de multa, o citado autor afirma que,

mesmo que considerada legalmente como sendo dívida de valor, a multa é ainda uma das três modalidades de penas previstas pelo art. 32 do Código Penal, razão pela qual pelo simples fato de, a partir da vigência da Lei $n^{0} 9.268 / 1996$, ser inscrita como dívida ativa da Fazenda Pública, passível tão somente de execução, não sendo mais permitida sua conversão em pena privativa de liberdade, não perdeu ela sua natureza penal e como tal deverá ser tratada, impedindo-se a sua cobrança após a morte do autor da infração. (Greco, 2000, p. 76)

Tal entendimento deve ser adotado, por analogia, aos casos de infrações administrativas, vale dizer, quando a Administração determina a incidência de uma pena por violação a alguma medida prevista, o cumprimento de tal sanção não pode ultrapassar a pessoa do condenado, em respeito ao citado princípio constitucional. Este é o entendimento de nossos Tribunais, conforme se vê dos seguintes arestos proferidos pelo Tribunal Regional Federal da 5ª Região, naquilo que interessa:

ADMINISTRATIVO - APREENSÃO DE VEÍCULO - MERCADORIAS ESTRANGEIRAS SEM PROVA DE INTRODUÇÃO REGULAR NO PAÍS - PERDIMENTO DO BEM - RESPONSABILIDADE DO PROPRIETÁRIO DO VEÍCULO - AUSÊNCIA DE COMPROVAÇÃO - MANUTENÇÃO SENTENÇA - 1. Trata-se de apelação e remessa oficial da sentença que concedeu a segurança para determinar à autoridade impetrada que proceda à restituição ao impetrante do veículo (cavalo) marca Scania/T124-GA4x2NXZ 400, ano de fabricação 2002, placa CYN 9161/PE e do semirreboque carreta SR GR TR, ano de fabricação 1995, placa KFP 0958/PE, ficando sem efeito eventual decisão administrativa de perdimento dos referidos bens. 2. O impetrante é o proprietário dos bens apreendidos pela Receita Federal em decorrência da lavratura, em seu nome, do Auto de Infração de no ${ }^{\circ}$ 430100/00265/08. 3. Foi ainda lavrado Auto de Prisão em Flagrante pelo Departamento de Polícia Federal, com o interrogatório dos conduzidos e a ouvida das testemunhas. 4. Colhendo informações acerca do Inquérito Policial de no ${ }^{\circ}$ 1768/08, junto ao sítio da Seção Judiciária da Paraíba, consta-se que este ainda encontra-se em andamento. 5. O Ofício de no 1648/08-Delefaz, do Delegado 
da Receita Federal no Estado da Paraíba, endereçado ao o Delegado de Polícia Federal, consta a informação de que nos autos do Inquérito Policial de n⿳0 117/08$\mathrm{SR} / \mathrm{PB}$, não foi constatada, diante das provas elencadas nos autos, a participação do impetrante, proprietário do caminhão e do semirreboque apreendidos pela Receita Federal, no suposto delito. 6. Os depoimentos constantes dos autos do Inquérito Policial não fazem qualquer referência à pessoa do impetrante. 7. Não havendo comprovação de qualquer participação do impetrante - proprietário dos bens apreendidos - no ilícito descrito no Auto de Infração e no Inquérito Policial referido, não há como manter à apreensão procedida. 8. Não se pode olvidar a aplicação analógica ao direito administrativo (quanto à penalidade), do princípio penal da intranscendência, ou da pessoalidade da pena, pelo qual a penalidade definida como ilícito não pode transcender à pessoa que é autora ou partícipe do delito. 9. A hipótese não é de aplicação da Súmula no 341 do STF, que prescreve que "é presumida a culpa do patrão ou comitente pelo ato culposo do empregado ou preposto", por não versar a ação acerca da reparação civil, mas sim de afastamento da pena administrativa de perdimento aplicada aos bens do impetrante em razão da apreensão. 10. Apelação e remessa oficial improvidas. (AP-Reex 2390, Relator o Desembargador Federal Emiliano Zapata Leitão, DJe 17.02.2011, grifos nossos)

CONSTITUCIONAL - ADMINISTRATIVO - SERVIDOR - INFRAÇÃO NÃO SUJEITA À PENA DE DEMISSÃO - IMPOSSIBILIDADE DE APLICAÇÃO - MEMBRO DE COMISSÃO DE LICITAÇÃO - SOLIDARIEDADE RESTRITA AO ÂMBITO CÍVEL - INTELIGÊNCIA DO ART. 51, § 3ํㅡㄹ DA LEI № 8.666/1993 - CONTROLE JUDICIAL DO ATO DE DEMISSÃO - CABIMENTO - PRINCÍPIOS DA LEGALIDADE, RAZOABILIDADE E PROPORCIONALIDADE - 1. Se a nenhuma das infrações administrativas atribuídas ao autor é expressamente cominada pena de demissão, não poderia a Administração aplicá-la. Como se sabe, a Lei no ${ }^{8} .112$, de 1990, adota o princípio da tipicidade da pena de demissão, cominando-a expressamente quando cabível. O administrador não tem qualquer discricionariedade na definição da pena a ser aplicada quando se trata de demissão. Ou ela é expressamente prevista por lei para infração, ou não pode ser aplicada. Por isso, quando a Administração a aplica sem respaldo legal, o ato punitivo padece de ilegalidade. 2. Equivocaram-se os órgãos da administração central, ainda, ao aplicar a regra do art. 51, § $3^{\circ}$, da Lei $\mathrm{n}^{\circ}$ 8.666, de 1993, para considerar os servidores processados administrativamente responsáveis entre si. A responsabilidade solidária prevista no mencionado dispositivo legal somente incide no âmbito cível, para fim de indenização (da própria Administração ou de terceiros). Na seara criminal ou administrativa penal, há normas constitucionais a impedir-lhe a incidência. Trata-se do art. $5^{\circ}$, incisos XLV e XLVI, da Constituição da República, que consagram os princípios da intranscendência e da individualização da pena 3. Esses dispositivos, embora previstos constitucionalmente apenas para as infrações penais, têm aplicação analógica no direito administrativo penal, pois em ambas as situações há a figura do infrator de norma proibitiva e a aplicação de sanção por conduta ilícita. Aliás, neles tem inspiração regra contida no art. 128 da Lei $n^{\circ}$ 8.112, de 1990, segundo a qual "na aplicação das penalidades serão consideradas a natureza e a gravidade da infração cometida, os danos que dela provierem para o serviço público, as circunstâncias agravantes e atenuantes e os antecedentes funcionais". 4. "Não significa invasão no âmbito discricionário do 
mérito do ato administrativo a análise, pelo Poder Judiciário, dos aspectos referentes aos princípios da legalidade, proporcionalidade e razoabilidade de decisão administrativa que pune o servidor público com a perda de seu cargo" (TRF5, Apelação Cível no 425900, Rel. Des. Fed. Ivan Lira de Carvalho, Quarta Turma, DJ 09.01.2008, p. 657, nº 6). 5. Apelação improvida. (AC 427852, Relator o Desembargador Federal Francisco Barros Dias, DJe 12.11.2009, grifos nossos)

Por sua vez, reza o caput do art. 14 da Lei no 6.938/1981 que "[...] o não cumprimento das medidas necessárias à preservação ou correção dos inconvenientes e danos causados pela degradação da qualidade ambiental sujeitará os transgressores" às penalidades previstas nos seus incisos. Desta forma, também se trata de responsabilidade subjetiva, uma vez que o caput não abarca os poluidores, mas sim especificamente os transgressores, ou seja, aqueles que por sua ação ou omissão não cumpriram com as medidas necessárias à preservação ou correção dos inconvenientes e danos causados pela degradação da qualidade ambiental. Assim, as penalidades administrativas previstas nos incisos do citado artigo sujeitam-se ao princípio da intranscendência das penas, diferentemente do contido no $\S 1^{\underline{o}}$ do mesmo artigo, que prevê expressamente a responsabilidade objetiva nos casos de indenização ou reparação em face de danos ambientais, não estando, portanto, sujeita ao referido princípio constitucional.

\section{CONCLUSÃO}

No caso concreto, o Tribunal Regional Federal da 4ㄹ Região considerou como parte legítima, para figurar no polo passivo da execução fiscal para cobrança de multa imposta pelo Ibama, o então proprietário do imóvel objeto de desmatamento ilegal, mesmo sendo tal execução proposta originalmente em face do seu pai, autor do fato, ao argumento de que a responsabilidade por dano ambiental é objetiva, solidária e propter rem, respondendo pelos danos ao meio ambiente perpetrados antes da alienação do imóvel tanto o alienante quanto o adquirente.

Entretanto, segundo o acórdão proferido pelo Superior Tribunal de Justiça, o recorrente não pode figurar como parte legítima para figurar no polo passivo de tal ação executiva, já que a aplicação de penalidades administrativas deve obedecer à teoria da culpabilidade, vale dizer, a conduta deve ser praticada pelo transgressor, com culpa ou dolo, além de haver nexo causal entre a conduta e o dano.

Em nosso entender, correta a decisão proferida pela citada Corte Superior, haja vista que os princípios dogmáticos do direito penal, entendidos como garantia do cidadão frente ao poder punitivo estatal, não podem ser relativizados ao argumento de uma maior proteção ambiental. No caso, foi 
aplicada uma multa pelo Ibama devido à ocorrência de um desmatamento ilegal praticado pelo pai do então autor do recurso especial. Dessa forma, o recorrente não poderia responder por ato ilícito praticado por seu pai, já que, tratando-se de responsabilidade administrativa por dano ambiental e/ou sanção penal prevista na Lei no 9.605/1998, deve ser observado o princípio garantidor da intranscendência das penas, aplicável a todo o direito sancionador, seja na esfera penal ou administrativa. Isso significa que a penalidade definida como ilícito não pode transcender à pessoa que é autora ou partícipe do delito. Assim, como a Lei no 9.605/1998 trata especificamente de crimes e infrações ambientais, na aplicação de seus preceitos, deve ser observada a referida teoria da culpabilidade, não sendo possível haver a aplicação da responsabilidade objetiva em tal caso. Da mesma maneira, pela própria dicção contida no caput do art. 14 da Lei no 6.938/1981, percebe-se que as penalidades previstas nos incisos de tal artigo devem ser aplicadas especificamente aos transgressores, vale dizer, somente aos causadores dos danos ambientais, o que reforça a aplicação da referida teoria para a aplicação das sanções ali determinadas.

\section{REFERÊNCIAS}

BENJAMIN, Antonio Herman V. Responsabilidade civil pelo dano ambiental. Revista dos Tribunais, São Paulo, v. 5, p. 75-136, 2011.

BRASIL. Constituição da República Federativa do Brasil, de 5 de outubro de 1988. 11. ed. Porto Alegre: Verbo Jurídico, 2010.

FIORILlO, Celso Antonio Pacheco. Curso de direito ambiental brasileiro. 8. ed. São Paulo: Saraiva, 2007.

GRECO, Rogério. Direito penal: lições. 2. ed. Belo Horizonte: Ed. do Autor, 2000.

MACHADO, Paulo Affonso Leme. Direito ambiental brasileiro. 18. ed. São Paulo: Malheiros, 2010.

NETO, Sebastião José de Assis. Responsabilidade civil por danos ambientais: questões pontuais. Disponível em: <http://www.impetus.com.br/data/jpf_article/36/file/responsabilidadecivilpordanoambiental_sjassisneto.pdf>. Acesso em: 10 set. 2012. 